\title{
Impact of Stock Market on Economic Growth Evidence: Dar-es Salaam Stock Exchange - Tanzania
}

\author{
Ali Othman Abbas, Yu Xin Pei, Zhang Rui \\ School of Accountancy, Jiangxi University of Finance and Economics, Nanchang, China \\ Email address: \\ abbasal14@hotmail.com (A. O. Abbas),yuxinpei@126.com (Yu Xin Pei),jxufechen@163.com (Zhang Rui) \\ To cite this article: \\ Ali Othman Abbas, Yu Xin Pei, Zhang Rui. Impact of Stock Market on Economic Growth Evidence: Dar-es Salaam Stock Exchange - \\ Tanzania. Journal of Finance and Accounting. Vol. 4, No. 6, 2016, pp. 321-327. doi: 10.11648/j.jfa.20160406.12
}

Received: September 19, 2016; Accepted: October 5, 2016; Published: November 17, 2016

\begin{abstract}
The objective of the study was to establish relationship between the stock market measures and economic growth in Tanzania. In order to achieve the objective, we need to examine the impact of stock market capitalization, total value of share traded and turnover on Tanzanian economy based on the time series data from 2000 - 2011. The unit root test and wnteestq (Portmanteau) tests were carried out. The findings suggest that Dar-es Salam Stock Exchange (DSE) has no effect on economic growth of Tanzania. We recommended that Tanzania government should establish financial policies, in order to encourage companies develop financial stock market culture, and enhance to push companies to initiate Initial Public Offering (IPO) instead of bank loans when money is needed to increase their investment.
\end{abstract}

Keywords: Market Capitalization Ratio, GDP Growth, Total Value of Shares Traded Ratio, Turnover Ratio

\section{Introduction}

All over the world, the capital market has played significant roles in national economic growth and development. One intermediary in the market that operates as a rallying point for the overall activities is the stock exchange. It is a common postulation that without a functional stock market, the capital market may be very illiquid and unable to attract investment, [8]. Stock exchange contributes to capital formation and investment risk reduction by offering opportunities for portfolio diversification [12]. Economists as well as financial analysts claim that, the investment that promotes economic growth and development requires long term fundings, far longer than the duration for which most savers are willing to commit their funds. The long term fundings can be undertaken smoothly by using capital markets. Capital market is a collection of financial institutions set up for the granting of medium and long term loans, [16]. Over the past few years, the world stock markets have surged, and emerging markets have accounted for a large amount of this boom. In Africa, few stock markets have been established in some countries like Swaziland, Zambia, Malawi, Uganda, and Ghana. Before 1980's few stock markets in sub-Saharan Africa and North Africa were established. As times goes, the number of stock markets is increasing to the extent that almost all African countries have got their own stock markets though they differ in size. Stock market development has been central to the domestic financial liberalization programs of most African countries. It seems any program of financial liberalization in Africa is incomplete without the establishment and development of stock markets [21]. The drive towards the establishment of stock markets in African countries during the last few decades might be linked to other vital factors for development of the global economy. The financial markets of many advanced countries have undergone tremendous changes and become increasingly integrated. These developments in the financial systems of developed countries have led them to seek liberalization in the international trade and exchange of services in world business negotiations. The establishment of stock markets in African countries and the liberalization of capital accounts can be seen as part of this global liberalization trend [3]. The establishment of stock markets in Africa was expected to increase the domestic savings and promote the quantity and quality of the investments. Moreover, stock exchange markets are taken as financial tool boosting the operations of the domestic financial system in general and the capital market in particular [11]. Critics, however, argue that the stock market might not perform efficiently in developing countries and 
that it may not be feasible for all African markets to promote stock markets given the huge costs and the poor financial structures [18]. An organized and managed stock market stimulates investment opportunities by recognizing and financing productive projects that lead to economic activity, mobilizes domestic savings, allocate capital proficiency, help to diversify risks, and facilitate exchange of goods and services. Undoubtedly, stock markets are expected to increase economic growth by increasing the liquidity of financial assets, make global and domestic risk diversification possible, promote wiser investment decisions, and influence corporate governance, i.e., solving institutional problems by increasing shareholders' interest/value [20]. In addition, stock markets are best indicators to forecast future economic activity and describe actual casual affect between future economic growth and stock prices. Contrary, the relationship between stock market development and real economic growth can be explained as any change in stock market will eventually change the cost of rental capital. If the firm's cost of borrowing will become high as compared to return of the investment, it slows down the growth of the economy. Furthermore, stock markets play an important role in allocation of capital to corporate sectors that in turn stimulate real economic activity. Many countries were facing financial constraints particularly developing countries, where bank loans are restricted to some favorable groups of companies and personage investors. This limitation can also reflect constraints in credit markets [13]. Due to stagnant banks' return from lending to specific groups of borrowers, these returns do not increase as the interest rate to borrowers rises [19]. Efficient stock markets provide guidelines as a means to keep appropriate monetary policy through the issuance and repurchase of government securities in the liquid market, which is an important step towards financial liberalization. Similarly, well-organized and active stock markets could modify the pattern of demand for money, and would help create liquidity that eventually enhances economic growth [16]

\section{Literature Review}

The relationship between financial development and economic growth has been an important issue of debate. Numerous studies have dealt with different aspects of this relationship at both theoretical and empirical levels. Traditional growth theorists believed that there is no correlation between stock market development and economic growth. According to [17], stock markets are not necessary institutions for achieving high level of economic development. Many viewed stock market as an agent that harms economic development due to their susceptibility to market failure, which is often manifested in the volatile nature of stock markets in many developing countries. Similarly, [2] indicates that the volatility of stock markets may reduce the ability of the public to supervise a company's investment efficiency. In addition, the public may increase investment returns by speculating in the stock market, hence the stock market development may be unfavorable to the economic growth. [1], employed time series data for five developed economies, namely Germany, United States, Japan, United Kingdom and France to examine the relationship between stock market development and economic growth. On the basis of their findings, they noted that bank based financial systems may be able to promote long term growth better than the stock market. According to them, the stock market does contribute to growth but in a smaller dimension when compared with banking system. [4] Considered the links between stock exchanges and overall socio-economic development to be tenuous, nonexistent or even harmful. He advised African countries not to devote further scarce resources and efforts to promoting stock exchange, since there are many weightier problems to address in Africa: high poverty levels, inadequate social services and undeveloped infrastructure. Even if the resources were available, stock markets could expose already fragile developing economies to the stabilizing effects of short-term, speculative capital inflows. Contrary to traditional view there are evidences that support the hypothesis that there is long run correlation between stock market development and economic growth. [5] found that various measures of stock market activity are positively correlated with measures of real economic growth across countries, and that the association is particularly strong for developing countries [10], examined stock market growth nexus and exhibited positive causal correlation between stock market development and economic activities. Similarly, [6] elaborated that the nexus between stock returns and output growth and the rate of stock returns is a leading indicator of output growth [7], showed that stock markets make a significant contribution to economic growth and development, that sustainable development of an economy could hardly take place without avenue to raise long term financing. [6], indicated that, using stock market indicators, the relationship between stock market and economic growth was predicted to be positive and with a reverse relationship. Furthermore, [15] shows that international risk sharing through internationally integrated stock markets improves resource allocation and can accelerate the rate of economic growth. [9] examined the macroeconomic determinants of stock market development in a sample of Latin American and Asian countries. The results show that GDP growth, domestic investment, and financial intermediary sector development are important factors. [16] found that a percentage point increase in financial intermediary sector development tends to increase stock market development in Africa by 0.59 points, controlling for macroeconomic stability, economic development, and the quality of legal and political institutions [7], investigated the relationship between stock market growth and economic growth, financial liberalization, and foreign portfolio investment in 40 emerging markets between 1980 and 2000. The result shows that economic growth, financial liberalization policies, and foreign portfolio investments were the leading factors of the emerging stock markets growth. Given these conflicting views, it is left to empirical investigation to determine whether or not stock market development accelerates economic growth in Tanzania. 


\section{Research Methodology}

The choice of a research design is determined by the nature of the problem and the method of data collection used, the conceptual structure within which the research is conducted, the basic plan guides collection, measurement and analysis of data. It is the framework that specifies the types of information to be collected, source of data and data collection procedure. This research is a case study design. It is a procedure of studying or collecting information within the organization. Under this design, the study is flexible in using different tools of data collection. This design is useful because the study is based on a specific area of the problem. The study is a correlation type of descriptive research that attempts to analyze the quantitative effects of stock market development on economic growth. The study therefore employed a time series analysis to examine the effect of stock market development and economic growth. The linear regression between the dependent and independent variables was determined. Stock market development is quantified by the ratio of value of listed shares per GDP, the total value of shares traded on the stock market exchange per GDP and the value of total shares traded per market capitalization. Data were collected from annual and periodic bulletin for the Central Bank of Tanzania's (BOT), DSE, and Tanzania Bureau of Statistics. STATA software was used for data analysis of the different variables. The study was conducted at the Dar-as-Salaam region for simplification of the work especially for availability of data. The researcher had to select this area by knowing that most of organizations in African countries their websites are not up dated, thus it could be so difficult to get current and reliable data through the web. The DSE has no branch in any region in Tanzania; its office is located only in Dar es Salaam region. Furthermore, it is placed where many of professional researchers are available for assistance. Strongly, this selection has been taken on board due to the financial and time constraints of the researcher.

Model Specification

The econometric model used in the study was-:

$\operatorname{GDP}_{\text {it }}=\alpha+\beta_{1}\left(\mathrm{MCR}_{\mathrm{it}}\right)+\beta_{2}\left(\mathrm{STR}_{\mathrm{it}}\right)+\beta_{3}\left(\mathrm{TR}_{\mathrm{it}}\right)+\varepsilon$

Where:

GDP Gross Domestic Product

MCR Market Capitalization Ratio

STR Total Value of Share Traded Ratio

TR Turnover Ratio

$\alpha$ Intercept/constantan

$\beta_{1} \beta_{2} \beta_{3}$ Responsiveness coefficient of independent variable to dependent variable

$\epsilon$ Error term

\section{Results and Discussion}

In this part the results of the study were analyzed and the interpretations of the findings given from the model. It contains three parts that is trend of variables, summary statistics and unit root tests of the variables, and finally Multicollinearity and other statistical tests with interpretation of the result.

\subsection{Trend of Variables}

(i) Stock Market Variables

Market Capitalization Ratio (MCR): This measure equals the value of listed shares divided by GDP. The assumption behind this measure is that the overall market size is positively correlated with the ability to mobilize capital and diversify risk on an economy-wide basis. Market capitalization has been growing over years as a result of increased listing and price appreciation of listed Securities. Between 2004 and 2006 the trend went up sharply due to a number of new companies being listed in the market.

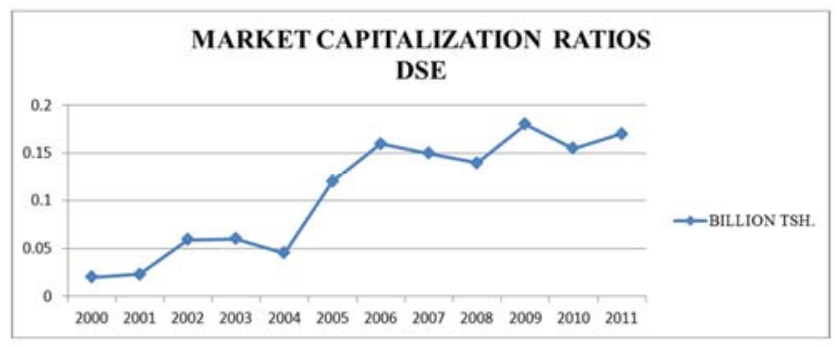

Figure 1. Market Capitalization Ratio.

(ii) Total Value of Shares Traded Ratio (STR)

The total value traded ratio measures the organized trading of firm equity as a share of national output and therefore should positively reflect liquidity on an economy-wide basis. The total value traded ratio complements the market capitalization ratio, although a market may be large or may do little trading. The trend is almost normal, it was swinging depending on variation of market turnover and the GDP movement as shown in the figure below.

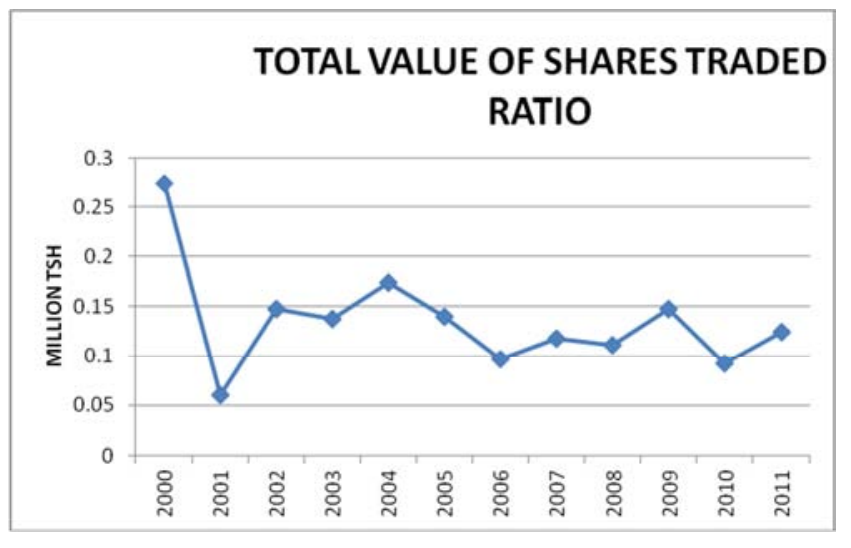

Figure 2. Total value of shares traded ratio.

(iii) Turnover Ratio (TR):

The turnover ratio complements the market capitalization ratio. 


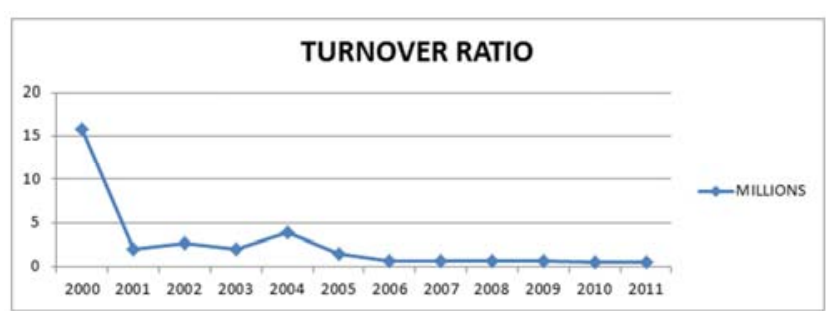

Figure 3. Turnover Ratio.

A large but inactive market will have a large market capitalization ratio but a small turnover ratio, also complements the total value traded ratio, while the total value traded ratio captures trading relative to the size of the economy and measures trading relative to the size of the stock market. A small liquid market will have a high turnover ratio but a small total value traded ratio. Market turnover has been varying significantly from year to year. Turnover depends on listing and trading activities carried out during yearly, celeries Paribas.

(iv) Annual Percentage of GDP Growth

At the beginning of 2000 the economy of Tanzania was positively responding with time, meaning there was an upward trend of economy. From 2004 to 2006 the trend was down ward direction probably due to the General Election, since Tanzania is among LDCs as others which are much affected by political issues by directing more economic recourses in politics rather than in economy. Apart from that, the movement was relatively upward and downward swing.

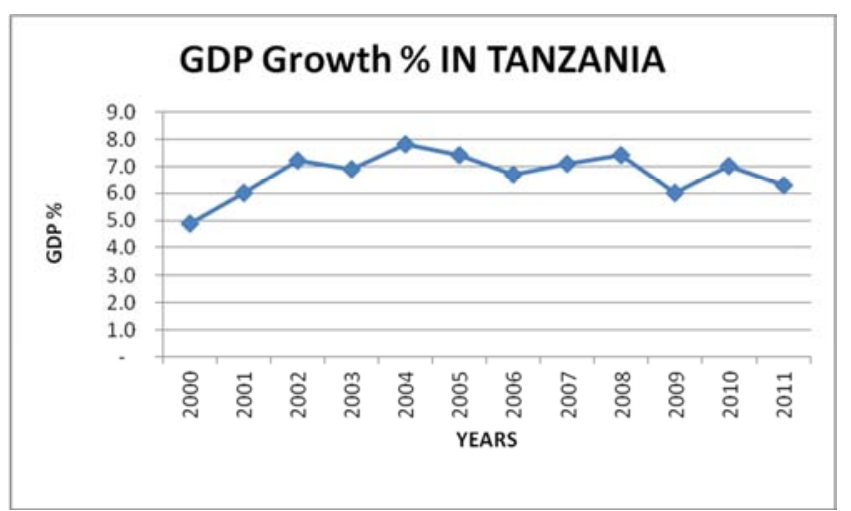

Figure 4. Percentage of GDP Growth in Tanzania.

\subsection{Statistics and Unit Root Tests}

The analysis started at looking at summary results of original variables before undertaking any statistical test.

(i) Normality of the data

The linear regression model was used in conducting the study. Apart from that, the purpose led the researcher to look at other Ordinary Least Square assumptions in order to avoid wrong interpretations that might be caused by false results.

Table 1. Summary of Statistical data before Transformation.

\begin{tabular}{lllll}
\hline & GDP & MCR & STR & TR \\
\hline Observation & 12 & 12 & 12 & 12 \\
mean & 6.725 & 0.0974064 & 0.135286 & 2.774131 \\
\hline
\end{tabular}

\begin{tabular}{lllll}
\hline & GDP & MCR & STR & TR \\
\hline std. Dev & 0.803543 & 0.0602647 & 0.053163 & 4.064883 \\
Variance & 0.645682 & 0.0036318 & 0.002826 & 16.52327 \\
Skewness & -0.89197 & 0.0518136 & 1.34873 & 2.716222 \\
Kurtosis & 3.212872 & 1.303477 & 5.077754 & 8.998173 \\
$\min$ & 4.9 & 0.017888 & 0.059913 & 0.059913 \\
Max & 7.8 & 0.177079 & 0.273817 & 0.2738117 \\
\hline
\end{tabular}

Normality of data is looked through Skewness which is around three and Kurtosis which is around zero. Unfortunately, the data in table 2 are not in normal distribution boundary thus they had to be transformed. The table below shows the summary of transformed data by using cubic root for GDP, log for STR and TR transformed by square root. According to the STATA results through ladder command, the used transformation methods were the best of the rest. At this stage there was no need for transformation of MCR since there was no difference before and after the transformation.

Table 2. Summary of Statistical data after Transformation.

\begin{tabular}{llll}
\hline & GDP1 & Log Str & TR1 \\
\hline Observation & 12 & 12 & 12 \\
mean & 315.6773 & -2.064235 & 0.8890085 \\
std. Dev & 100.41 & 0.3714859 & 0.335807 \\
Variance & 10082.16 & 0.1380018 & 0.1127664 \\
skewness & -0.4030755 & 0.0303826 & -0.446577 \\
Kurtosis & 2.472588 & 3.616572 & 1.920036 \\
min & 117.649 & -2.814862 & 0.255593 \\
Max & 474.552 & -1.295295 & 1.28675 \\
\hline
\end{tabular}

(ii) Unit Root Test.

The researcher decided to undergo this test so as to know whether the data are stationary or not. Augmented DickeyFuller (ADF) technique was used to test stationary of data. $5 \%$ critical value was taken as the level of significance since it is more reliable than $1 \%$ and $10 \%$. Also by taking into account large proportion of data, the researcher prefers $5 \%$ to other levels of significance.

Table 3. Summary of data before differencing at any level.

\begin{tabular}{lll}
\hline Variable & T. statistic & Critical value 5\% \\
\hline GDP1 & -3.178 & -3.00 \\
MCR & -1.120 & -3.00 \\
LOGSTR & -7.108 & -3.00 \\
Tr1 & -2.012 & -3.00 \\
\hline
\end{tabular}

The results above show that GDP1 and Logstr are stationary since the test statistical results are greater than critical value (-3) unlike Mcr and Tr1 which their test statistical results are lesser than critical value at 5\% level of significance. Thus the researcher had to differentiate non stationary data at one level of difference.

Table 4. Summary of non stationary data at one level of difference.

\begin{tabular}{lll}
\hline Variable & T. statistic & critical value $\mathbf{5 \%}$ \\
\hline GDP1 & -3.178 & -3.00 \\
MCR1 & -3.449 & -3.00 \\
LOGSTR & -7.108 & -3.00 \\
Trd1 & -3.874 & -3.00 \\
\hline
\end{tabular}


After generating new variables by differentiating non stationary data at once, the table above show, ADF results enabled the researcher to reject the null hypothesis which states that, there is unit root test (there is no stationary) and accepts the alternative hypothesis, meaning that now all data are stationary; therefore the study can process other tests.

\subsection{Multicollinearity Problem}

Multicollinearity may be perfect or imperfect and can be measured through either VIF or $F$ value. For $F$ value technique the explanatory variables are said to be highly correlated if the $\mathrm{F}$ value is statistically significant while $\mathrm{P}$ value of individual variable is insignificant. [14] Suggests that if a set of explanatory variables is uncorrelated, each VIF is equal to 1 . If the set is highly inter correlated then a VIF might even exceed 10. Other statisticians suggest that if VIF exceeds 5 , it is better for the researcher to find alternatives to least-square regression. Based on the above theories of Multicollinearity and the results from the model after regression, the calculated VIF is 2.68 which is even lesser than 5. Thus it did not influence the researcher to employ an alternative and find another model as suggested by some statisticians. This meant that the repressors are not in imperfect Multicollinearity problem and therefore it allowed the researcher to continue with the study.

Table 5. Least Square Regression.

\begin{tabular}{|c|c|c|c|c|c|c|}
\hline \multicolumn{7}{|c|}{ Reg gdpgrowth1 logstr mer1 trd1 } \\
\hline Source & Ss & Df & Ms & & $\begin{array}{l}\text { Number of obs } \\
F(3,7)\end{array}$ & $\begin{array}{l}=11 \\
=3.28\end{array}$ \\
\hline Model & 39793.7574 & 3 & 13264.5858 & & Prob $>f$ & $=0.0887$ \\
\hline Residual & 28329.8033 & 7 & 4047.11476 & & $\begin{array}{l}\text { R-squared } \\
\text { Adj R-squared }\end{array}$ & $\begin{array}{l}=0.5841 \\
=0.4059\end{array}$ \\
\hline Total & 68123.5607 & 10 & 6812.35607 & & Root MSE & 63.617 \\
\hline gdpgrowth1 & Coef. & Std. & Err. & $\mathrm{T}$ & $p>|t|$ & [95\% conf. interval] \\
\hline logstr & 341.79 & 115.9689 & 2.95 & 0.021 & 67.56707 & 616.0129 \\
\hline mer1 & -2502.852 & 1096.137 & -2.28 & 0.056 & -5094.804 & 89.10067 \\
\hline $\operatorname{trd} 1$ & 333.3326 & 170.8109 & 1.95 & 0.092 & -70.57097 & 737.2362 \\
\hline $\begin{array}{l}\text { cons } \\
\text { vif }\end{array}$ & 1069.769 & 246.7641 & 4.34 & 0.003 & 486.2648 & 1653.274 \\
\hline Variable & VIF & $1 / \mathrm{VIF}$ & & & & \\
\hline $\operatorname{trd} 1$ & 3.20 & 0.344706 & & & & \\
\hline logstr & 2.90 & 0.344706 & & & & \\
\hline morl & 1.94 & 0.514797 & & & & \\
\hline Mean VIF & 2.68 & & & & & \\
\hline
\end{tabular}

\subsection{Portmanteau Test}

The study had to test for serial autocorrelation, time series data are facing the problem of white noise.

Table 6 (a). Portmanteau Test before differencing.

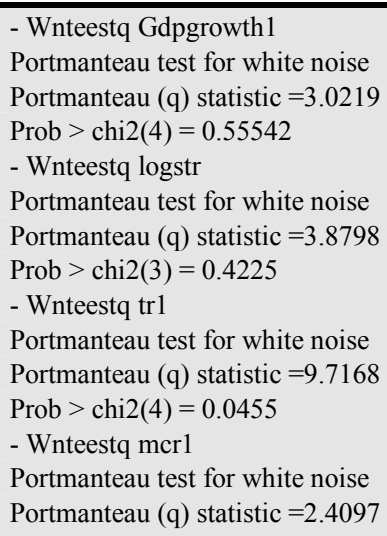

The study employed wnteestq technique at 0.05 level of significance for testing autocorrelation problem, table 6(a) above. The generated results show that only tr1 has the probability lesser than 0.05 which means, there is autocorrelation of variables. Unfortunately, after differencing at one level of difference the results have changed and showed that there is no autocorrelation between explanatory variables as shown in table 6(b) below.

Table 6 (b). Portmanteau Test after differencing.

- Wnteestq Gdpgrowth1
Portmanteau test for white noise
Portmanteau (q) statistic $=3.0219$
Prob $>$ chi2(4) $=0.5542$
- wnteestq mcr1
Portmanteau test for white noise
Portmanteau (q) statistic $=2.4097$
Prob $>$ chi2(3) $=0.4918$
- wnteestq logstr
Portmanteau test for white noise
Portmanteau $(q)$ statistic $=3.8798$
Prob $>$ chi2(4) $=0.4225$
- wnteestq trd1
Portmanteau test for white noise
Portmanteau (q) statistic $=2.7555$
Prob $>$ chi2(3) $=0.4309$

\subsection{Model Estimation}

The signs of all estimated coefficients were expected in the OLS model in table 7 below, the parameters of all variables are significant at $95 \%$ confident interval as shown below.

Gdpgrowth $1=1069.769$ -

$2502.852 \mathrm{mcr} 1+341.79 \operatorname{logstr}+333.3326 \operatorname{trd} 1$ 
According to the table below the relationship between economic growth and market capitalization is negative. This implies that, a unit increase of market capitalization will affect the economic growth negatively by 2502.852 units. Also there is no relationship between MCR and GDP. The relationship between the total values of share traded in the market and economic growth, the result shows that there is a positive relationship and its implication is, one unit rise of total value of share in the market will affect positively the economic growth of Tanzania by 341.79 units. According to regressed result as shown in table 7 , the relationship between turnover and economic growth are positively related. Economically, this relationship means whenever security turnover increases by one unit in the market the economy of Tanzania will increase by 33.3326 units. This gives sign to DSE and other interesting parts that the turnover is a crucial determinant not only for the growth of the economy but also for the market itself.

Table 7. Variable Parameters.

\begin{tabular}{|c|c|c|c|c|c|c|}
\hline Source & Ss & Df & MS & & Number of obs & $=11$ \\
\hline & & & & & $F(3,7)$ & $=3.28$ \\
\hline Model & 39793.7574 & 3 & 13264.5858 & & Prob $>f$ & $=0.0887$ \\
\hline Residual & 28329.8033 & 7 & 4047.11476 & & R-squared & $=0.5841$ \\
\hline Total & 68123.5607 & 10 & 6812.35607 & & Root MSE & 63.617 \\
\hline gdpgrowth1 & Coef. & Std. & Err. & $\mathrm{T}$ & $\mathrm{p}>|\mathrm{t}|$ & [95\% conf. interval] \\
\hline logstr & 341.79 & 115.9689 & 2.95 & 0.021 & 67.56707 & 616.0129 \\
\hline $\operatorname{trd} 1$ & 333.3326 & 170.8109 & 1.95 & 0.092 & -70.57097 & 737.2362 \\
\hline cons & 1069.769 & 246.7641 & 4.34 & 0.003 & 486.2648 & 1653.274 \\
\hline
\end{tabular}

From the above statistical measurements which involved a number of statistical tests as shown, the researcher came up with decision of starting that DSE has no strong impact in the GDP of Tanzania. It might be due to fewer companies listed in DSE or stock trading culture which is caused by failure of people to know how the stock market can benefit them and its importance.

\section{Conclusion and Recommendations}

The study sought to examine the impact of DSE on the economic growth of Tanzania through GDP evolution using time series data from 2000-2011. The findings suggest that there is no strong effect between DSE and economic growth for Tanzania. Furthermore, the results indicated that stock market is not influencing Tanzania's economic growth because the Adjusted R-Squared is below 50\% meaning the explanatory variables are unable to explain the economic growth even for half way, the same as probability which is so huge compared to acceptable $5 \%$ level of significance. The research results do not match with the other authors' findings who confirm a positive relationship between stock market development and economic growth. [21, 8, 9, 2, 17, 19]. We recommend that the government should encourage savings and investment by appropriate policies including reducing tax burden from official employment employees deducted from monthly salaries as a payee contribution and removing taxes imposition to a number of allowances earned by private companies' staff as it does to central government employees. Also it should closely supervise the financial institutions such as Banks, Insurance companies and social security funds which have either direct or indirect influence on investments done through Stock market. For example, whenever commercial banks reduce an interest rate many investors will divert to borrow from banks instead of going to stock market. For the case of Pension funds, the pension funds of Tanzania affect much the saving rate of pensioners by charging more than $12 \%$ as operating costs from member's monthly contribution which is far away from international rate of 5\%. It implies that the amount of saving from a member becomes lower compared to what would be if the percentage rate of administrative cost charged by pension fund was about or below 5\%. In increasing the market capitalization, Tanzanian government can either transform its profitable enterprises to public companies or encourage new registered companies by providing sufficient incentives and preparing conducive environment apart from the existing ones. Tanzanian government through the Bank of Tanzania should review the DSE policy for opening doors to investors to participate in international security markets quickly and timely. Since, up to now, whoever Tanzanian wants to trade with in other security markets for example Lusaka or Nairobi security market should first seek permission from the Bank of Tanzania. The policy reduces the smoothness and a nice flow of security market transactions. The reflection of this policy is not only hindering the foreign investor to join hands with other Tanzanians in investing through DSE, but also affecting the growth of the market.

\section{References}

[1] Ake B. and Dehuan J., (2010). "The Role of Stock Market Development in Economic Growth: Evidence from Some Euronext Countries", International Journal of Financial Research, Vol. 1, No. 1, pp. 14-20.

[2] Ake, B and Ognaligui (2010). Financial Stock Market and Economic Growth in Developing Countries: The Case of Douala Stock Exchange in Cameroon. International Journal of Business and Management Vol. 5, No 33, pp16- 41.

[3] Antonios, A. (2010) Stock Market and Economic Growth: An Empirical Analysis for Germany. Business and Economics Journal, Volume 2010: BEJ-1. 
[4] Asante, S and Agyapong, D. (2011). Bank Competition, Stock Market and Economic Growth in Ghana International Journal of Business Administration Vol. 2, No. 4.

[5] Brambila Macias, J., and I. Massa (2009) 'The global financial crisis and sub-Saharan Africa. The effects of slowing private capital inflows on growth', ODI Working Paper 304. London: Overseas Development Institute.

[6] Charles, Y., \& Charles, A,. (2007). IMF Working Paper No. WP/07/209.

[7] Chen, Lee and Wong, (2004), Is Rate of Stock Returns a Leading Indicator of Output Growth? In Case of Four East Asian Countries.

[8] Deb S. G. and Mukherjee J., (2008). "Does Stock Market Development Cause Economic Growth? A Time Series Analysis for Indian Economy", International Research Journal of Finance and Economics, Issue 21, pp. 142-149.

[9] Ejibola, E. (2009), "Stock Market Development and Economic Growth: Evidence from Seven Sub-Sahara African Countries", Journal of Economics \& Business, Vol.61 (2), 162-171.

[10] El-Wassal, A. Kamal, (2005), "Understanding the Growth in Emerging Stock Markets," Journal of Emerging Market Finance, Vol. 4 (3), pp. 227-261.

[11] Ezeoha et all (2009). Stock market development and private investment growth in Nigeria, Journal of sustainable development in Africa, Volume 11, No 2.

[12] Hossain and Kamal (2010). Does stock market development cause economic growth? A time series analysis for Bangladesh economy? International Conference on Applied Economics.

[13] Kamuzora, Adam J, F (2013). Research Methods for Business and Social Studies, Morogoro: Mzumbe Book Project Tanzania.

[14] Kasekende, L. (2007). Financial Industry as a Catalyst for Economic Growth. Nigeria International Conference on Financial Sector Strategy, Abuja, June.

[15] Kirankabeş. M. C and Başarir, c (2012) Stock Market Development and Economic Growth in Developing Countries: An Empirical Analysis for Turkey. International Research Journal of Finance and Economics ISSN 1450-2887 Issue 87. Euro Journals Publishing, Inc.

[16] Mun,Long,Siong and Thing (2008) Stock Market and Economic Growth in Malaysia: Causality Test. Asian social science Vol.4 No 4

[17] Nazir, M.s, Nawaz M. M. and Javed U. (2010) Relationship between economic growth and stock market development. African Journal of Business Management Vol. 4(16), pp. 3473-3479.

[18] Nowbutsing B. M. and Odit M. P., (2009). "Stock Market Development and Economic Growth: The Case of Mauritius", International Business \& Economics Research Journal, Vol. 8, No.2, pp. 77-88.

[19] Obiyo, O. C, (2011). The impact of stock market operations on the Nigerian economy. Department of Accounting, Faculty of Management Sciences, University of Portharcourt, Nigeria.

[20] Vector, osei (2005), Does the Stock Market Matter in Ghana? A Granger-Causality Analysis, Bank of Ghana, WP/BOG$05 / 13$.

[21] Yusop and Liew (2005). Financial Development and Economic Growth in Malaysia: The Perspective of Stock Market. 